\title{
Author Spotlight: Bernard Stiegler's The Age of Disruption: Technology and Madness in Computational Capitalism
}

For many readers of this sometimes uncannily prescient and admirably prolific French philosopher, the first encounter with Bernard Stiegler came with his (at the current count) threevolume Technics and Time (Stiegler, 1994). In the first volume, The Fault of Epimetheus, Stiegler re-reads the familiar Greek myth in order to restage a philosophy of technics, a philosophy that denies the privileged position of the human which almost all theories and theorists of technology, whether they recognize it or not, take for granted. For readers of Management Learning who might be inspired to take the leap into Stiegler's body of work, I would suggest beginning with either one or two of the shorter texts - For a New Critique of Political Economy (Stiegler, 2010) and What Makes Life Worth Living (Stiegler, 2013) are both pithy insights into his central thesis - or one of his two most recent texts: Automatic Society vol. 1 (Stiegler, 2016) and The Age of Disruption (Stiegler, 2019). This recent work embeds his re-reading of technology into a wideranging enquiry into what he suggests is the general state of disillusion and delinquency affecting most of the developed world, and a state largely conditioned by our increasingly networked and digitally enabled hyper-industrial economies. As an academic concerned with the impact of digital technologies on business and management education, and as a reader of Management Learning, I find in Stiegler's work a continual and urgent provocation to ask what are the kind of pedagogic, management and organizational practices that could survive in such a climate, and to do so responsibly, usefully, and in such a way which might sustain the communities, societies, and political economies upon which they rely.

In The Age of Disruption, Stiegler suggests a contemporary malaise or disenchantment to be the product of a neoliberal, capitalist model of consumption which has increasingly been driven by the disruptive power of the technologies of 'progress'. At the same time, this is read alongside some occasional glimmers of how these same technologies, and the lives lived amongst them, might be re-enchanted through a more positive 'noetic' life, that is, a life in which an intergenerational transmission and translation of knowledge provides a profound foundation for 
social and individual well-being. Stiegler's project, then, is primarily a therapeutics, and one that positions technology at the 'default of origin', that is, as a quasi-essential supplement through which the very notion of the human, and its future, can be reinvented. This position allows us to ask important questions regarding the capability of educational institutions to respond to a climate in which the industrial scale deployment of networked digital technologies has led to a dissolution of the conditions for the formation of attention, the effect of which is an increasingly automated society, and one which encourages a short-sighted willingness to forego a long-term concern for the future; a position which, for Stiegler, fetishizes a certain barbaric, buccaneer madness, and has a contempt for reflective, sustained thought.

The result of all this, of course, is an intellectual race to the bottom; one happening at an alarming speed, and not least because it is conditioned by a consumerist model that has reached its limits: 'because it has become systemically short-termist, because it has given rise to a systemic stupidity that structurally prevents the reconstitution of a long-term horizon' (Stiegler, 2010; 5). Such systemic stupidity, then, is a result of the battle for the formation of attention which, at the last count, the market driven programming industries which seem to increasingly determine much of our political and social lives (industries represented by entities such as Google, Amazon, Facebook, Apple and Microsoft) have all but won. As Daniel Ross explains, the consequences of this for the future of education could be catastrophic:

Given that a large portion of this vast apparatus is systematically directed at children and youth - with the goal of interfering with the functioning of inter-generational authority and the transmission of intergenerational knowledge, reducing desire to the shortest-term satisfactions of consumerist behaviour, producing vicious circles and leading to the logic of addiction (where consumption perpetually increases and satisfaction perpetually decreases) - the deleterious effect on the possibility of every work of learning and teaching becomes obvious and undeniable, however often denied (Ross, 2019). 
To demonstrate this argument, Stiegler often refers to the global financial crash of 2008, and in a useful footnote in The Age of Disruption, the notion of systemic stupidity is read in relation to Alan Greenspan's explanation for missing the warning signs that led up to this event:

[...] Greenspan bore witness, in his replies during the Congressional hearing in Washington before which he appeared on 23 October 2008, to the fact that he himself was proletarianized by the automation of financial decision-making [...] Greenspan can summon up this alibi, and that doing so does not seem totally wrong or deceitful, only because the system is indeed based on a systemic dissimulation, the consequence of which is that risks are taken that can no longer be calculated at all other than by algorithms that make impossible any decision about the precise level of risk they involve [...] In this regard, the proletarianization of Greenspan himself is indeed actual' (Stiegler, 2019a; 367).

Stiegler's argument suggests that the automation of financial decision-making rendered it impossible for Greenspan to make decisions about the outcomes of such processes. But the appearance of 'overly complicated models' is just that, an apparition, one summoned by an algorithmically governed financial industry a symptom of which are heads of international finance whose proletarianized thought-processes short-circuit an understanding of that very industry. In this respect, Greenspan's alibi is both genuine and insincere: he did fail to understand the complex predictive models, but his response is like that of an automaton whose capacity to comprehend the complexities of algorithmic decision making has been designed out. We are, then, increasingly at risk of losing the intellectual capacity to understand our current situation, and thus incapable of spotting, let alone understanding, the inherent dangers toward which industrial scale, data-driven policy and decision making is taking us.

This example is, of course, not unfamiliar to readers of Management Learning. Several articles have also raised the question of how business and management education has at least partly contributed to the financial crisis, and several others have suggested possible foundations for change in its aftermath. Matt Statler summarizes the arguments of many of these commentators when he suggests that 'over the course of the history of the business school, the 
role of normative, practical knowledge has been eclipsed by value-free, scientific knowledge, culminating with the neoclassical notion that all human social interactions may be understood objectively in the aggregate as market forces (Statler, 2014). For Statler, one response to this might be a renewed focus on the accumulation of practical wisdom. Borrowing from Aristotle's notion of phronesis, and with all the necessary caveats, he posits that perhaps the "best thing anybody can do is to prepare oneself by training the habits of mind and body that are attuned to the world and yet reflexive about the limitations of our own knowledge and actions (Statler, 2014). Lancione and Clegg also suggest that one response to some of the post-crash challenges faced by business and management educators would be a similar focus on the question of how to provide students with the opportunities to ask how a critical and creative engagement with the world might lead to better judgment. With their emphasis on design, and on the business and management schools of the future affording spaces for critical and creative practice, they conclude that 'being reflexive about the spaces we work in and we contribute to reproducing is a step forward to a different mode of management learning' (Lancione \& Clegg, 2014).

Both of these responses highlight the importance of developing habits aimed towards an ethical and virtuous life, and ask how we might design such habits into business and management pedagogies. This complements Stiegler's focus on steering our activities towards maintaining the desire for the ideals that should suffuse every academic discipline as their incalculable horizon, ideals such as truth, beauty and justice. Such ideals are those forever out-of-reach objects of desire that condition all noetic activity, the capacity for which the short-circuiting of thought by the programming industries is at risk of eradicating. Indeed, for anyone trying to think through the implications of the financial crash on business and management pedagogies, his suggestion that there can be no economy without desire, and no credit without trust, might mean that a return to his reading of the libidinal economy in What Makes Life Worth Living (Stiegler, 2013), would be worth the trouble. What this should also highlight, however, is the urgency of asking such questions in educational institutions that are increasingly at risk from a certain proletarianisation of the mind.

This dilemma is addressed in the opening to Stiegler's 2015 text, Automatic Society vol. 1: The Future of Work, when he situates it in relation to Chris Anderson's claim that, in the age of 
big data, the requirement for theory based academic endeavor is limited, if not obsolete (Anderson, 2008):

Continuing with a form of reasoning similar to that which he applies to the epidemiology of Google, Anderson comes to the conclusion that what is referred to today as 'big-data' [...] no longer has any need for either theory or theorists - as if data 'scientists', specialists in the application of mathematics to very large databases through the use of algorithms, could replace those theoreticians that scientists always are in principle. (Stiegler, 2016: 1)

At stake here is the relationship between automation and intelligence, and of the reduction of thought to its manipulation by algorithmically driven digital networks. This leads to the most recent stage of a more general shift to proletarianization, whereby the process identified by Marx as the subsuming of manual skills into their mechanical reproduction, which then morphed into the mediatized capture of everyday life by the 'culture industries' - as identified by Horkheimer and Adorno (2002) - has shifted further still into its current stage, in which the very capacity to think is reduced to calculable elements which can be organized and manipulated by phenomena such as social media. For Stiegler, this leads to the 'systemic stupidity' already noted, whereby the failure to comprehend our lack of comprehension produces a world in which theory can be bypassed by data driven automated decision-making:

With the advent of reticular reading and writing (Herrenschmidt 2007) via networks made accessible to everyone through the implementation, beginning in 1993, of the technologies of the World Wide Web, digital technologies have led hyperindustrial societies toward a new stage of proletarianization-through which the hyperindustrial age becomes the era of systemic stupidity [...]. Such is also the case for digital networks. But through the latter, stupefaction and stupidity are being installed in a new and functional way: in such a way that disruption can structurally and systemically shortcircuit and bypass the knowledge of psychic and collective individuals. This is what will here be called "systemic stupidity." (Stiegler, 2019b) 
What is central here is Stiegler's reading of a new stage of technological development as the condition of a 'disruption' which short circuits the very institutions and organizations which may enable a thoughtful, careful consideration of that evolution. In other words, the disruption caused by industrial scale digital technology is pervasive to such an extent that it rapidly renders obsolete those institutions - such as universities - which might be able to think through the implications of that disruption. This is an alarming double-bind which Stiegler continually reaffirms, and which, when reading him, I continually come back to. Should it be true, it would mean that we could quite possibly be past the point at which this dissolution of the capacity to think can be reversed. At this point, one is also minded to consider the parallel trends of an inability to comprehend the impending climate catastrophe, a crisis in the ability to practice wise judgment and to lead amidst situations of increased complexity, as well as the apparent eradication of our so-called democratic institutions and their shrinking ability to deal with the implications of radical technological change; in all these cases the reaction is to retreat and to entrench populist agendas which speak to an increasingly resentful and anxious majority.

At this point it would perhaps be wise to ask to what point are we are all symptoms of the same 'systemic dissimulation', a dissimulation that promotes an inherently irresponsible risktaking, or dissociative apathy, as the only natural reactions to a world increasingly driven by an impenetrable algorithmic modelling. Is our capacity to judge our ability to make decisions in such a world compromised in advance? Again, this would highlight the importance of making space for critical and creative reflection in our educational institutions, but it also chimes with the central question of The Age of Disruption, which asks how we have let this systemic tendency towards irresponsibility and stupidity masquerade under the guise of innovation and disruption, particularly when the prevalence of the latter seems to come at the cost of a certain care for the irreducible bond between the individual and the social:

Disruption essentially consists in outstripping and overtaking social organizations, and, through that, in short-circuiting collective individuation and transindividuation. Disruption, then, is based on the destruction of every psychosocial structure that enables the construction of such an economy - an economy that is simultaneously and 
indissolubly psychic and social, which means that changing the social also changes the psychic. (Stiegler, 2019a; 81).

A focus on the destruction of psychosocial structures allows Stiegler, following the work of Peter Sloterdijk (Sloterdijk, 2014), to develop the fascinating link between delinquency and what many might refer to as progress. Indeed, in a remarkable section from The Age of Disruption, he links the hubris of neoliberal globalization with an increasing tendency towards disinhibition, a tendency which links Silicon Valley to the White House, as well as to the attacks on London Bridge and the anger of the Parisian banlieue; each example channeling a certain nihilist disenchantment as the legitimation for drive-based violence, a violence arising 'without a therapeutic'. This marks a point at which the systemic stupidity as demonstrated in 2008 has morphed into the generalized madness of our present moment, itself an especially dangerous stage in that such disinhibited barbarism is quickly becoming normalized through our politics, economic policy and industrial strategies.

This shift to a focus on madness makes it possible for Stiegler to hold together the notions of neoliberal disruption with terrorism and the artist-genius; a crucial series of themes in that Stiegler seems to posit a very fine line between what might ruin us, and what might save us. But in doing this Stiegler also runs the risk of suffering from the same dilemma which, from Descartes onwards, impacts anyone who tries to summon the term 'madness' in order to delimit it, define it, and make it work for them. Indeed, because the precise meaning and location of madness is impossible to define once and for all, anyone who tries to stake a claim to this term is reducing to calculable rationalism the very thing which they are trying to describe as somehow beyond the rational. Stiegler may be wise to this of course, not least when he states that the 'possibility of madness is the condition of reason, and so to speak, its reason'. But on the same page he also states that madness is that which 'possesses the barbarians' as their hubris, and as that which is 'manifested in the kind of 'end of an era' behavior that accompanies all great collapse' (Stiegler, 2019a; 40). Nevertheless, Stiegler is onto something in his relating of a certain productive madness to a disruptive hubris, not least in the way that the hubristic madness as demonstrated by the disruptive 'barbarians' of French entrepreneurism, seems only one remove from the 'delirious' dreaming Stiegler himself encounters as he cycles through the Bourbonnais dictating 
his work into a machine, or the 'possibility of madness' which Stiegler turns into a 'source and resource' of positive, noetic enterprise during his incarceration in 1983 (the story of which is also fascinating, in the sense of it being a bildungsroman or pedagogic autobiography which intermittently surfaces through into the more condensed philosophical work) (see, for example: Stiegler, 2019a; 310). Madness, then, for Stiegler as for many others, appears to be a doubleedged; much like Plato's pharmakon, and the philosophy of technics it provokes, Stiegler's oeuvre touches on what is at once both the poison and the cure. ${ }^{1}$

In closing it is also worth noting Stiegler's repeated focus on the notion of the transitional object. This refers to a theory of childhood development as conditioned by early object relations, and was first proposed by the psychoanalyst Donald Winnicott. The transitional object returns again and again in Stiegler's work as a demonstration of the relationship between technology and education. This, for me, approaches the more positive aspect of Stiegler's project, and begins to outline a possible, and pragmatic, method of reenchanting our current malaise. It is also something which the programming institutions, those educational institutions that Stiegler opposes to the programming industries, can practically implement through pedagogies which counter the reductive, calculative and somewhat automatic programming of our children by reticulated digital technologies as exemplified by social media networks. What is missing from almost all Stiegler's work, however, and indeed in many similar readings of the digital milieu of our current age, is the necessary work on the question of sexual difference. The key perpetrators of hubristic madness, both positive and negative, are men, and the statistics and events he cites as evidence of a decline in morality, for example, and those which evidence an increase in disinhibition and a resurfacing of the death drive as the lack of a reason to live, are almost uniquely focussed on men. What is the significance of this omission for a history and theory of technology? And what might it say about the production and future of thought and knowledge in increasingly disruptive, hyper-industrial digital economies? To even begin to address such questions would, of course, require us to go much further afield. For the moment, however, it is perhaps enough to suggest that, in reading Stiegler's work, it is possible to identify such gaps

\footnotetext{
${ }^{1}$ For more on this it would be necessary to revisit Derrida's reading of the term in: Derrida, 1981, pp.62-171.
} 
against a backdrop of what is, at times, a quite brilliant articulation of some of the most pressing questions of our era.

\section{Bibliography:}

Alvesson, M. and Spicer, A. (2012), A Stupidity-Based Theory of Organizations. Journal of Management Studies, 49: 1194-1220. doi:10.1111/i.1467-6486.2012.01072.x

Anderson, C., (2008) 'The End of Theory: The data deluge makes the Scientific method Obsolete', Wired, https://www.wired.com/2008/06/pb-theory/

Derrida, J., (1981) 'Plato's Pharmacy', trans. Barbara Johnson in: Dissemination, London: The University of Chicago Press.

Horkheimer, M and Adorno, T. (2002) The Dialectic of Enlightenment: Philosophical Fragments, Stanford, Stanford university Press

Lancione, M., \& Clegg, S. (2015). The lightness of management learning. Management Learning, 46(3), 280-298. https://doi.org/10.1177/1350507614526533

Ross, D,. (2019) 'From 'Dare to Think!' to 'How Dare You!' and back again', Educational Philosophy and Theory, DOI: 10.1080/00131857.2019.1678465

Sloterdijk, P., (2014) In the world interior of capital: towards a philosophical theory of globalization, Cambridge: Polity.

Smith, A,. (1937) The Wealth of Nations, The Modern Library: London.

Statler, M. (2014). Developing wisdom in a business school? Critical reflections on pedagogical practice. Management Learning, 45(4), 397-417. https://doi.org/10.1177/1350507614541198

Stiegler, B., (1994) Technics and Time Vol. 1: The Fault of Prometheus, Stanford: Stanford University Press.

Stiegler, B., (2009) Acting Out, trans. D. Barison, D. Ross and P. Crogan. Stanford, CA: Stanford University Press.

Stiegler, B., (2010) For a new critique of political economy, trans. Daniel Ross, Cambridge: Polity press.

Stiegler B., (2011), "'Le grand désenchantement'. Un entretien avec le philosophe Bernard Stiegler", Le Monde, 21 February.

Stiegler, B., (2013) What makes life worth living: On pharmacology, London: Polity Press.

Stiegler, B., (2016) Automatic Society, vol. 1: The Future of Work, Cambridge: Polity.

Stiegler, B., (2019a) The Age of Disruption: Technology and Madness in Computational Capitalism, trans. Daniel Ross, Cambridge: Polity. 
Stiegler, B., (2019b) 'For a Neganthropology of Automatic Society'. In: Thomas Pringle, Gertrud Koch, Bernard Stiegler (Hg.): Machine. Lüneburg: meson press 2019, S. 25-47. DOI:

http://dx.doi.org/10.25969/mediarep/12237. 